\title{
Cristo cósmico y antropocentrismo en Leonardo Boff: una lectura desde la óptica reformacional
}

\author{
GONZALO DAVID \\ Seminario Teológico Presbiteriano José Manuel Ibáñez Guzmán (Chile) \\ gonzalodavid@gmail.com
}

\begin{abstract}
Resumen
Se presenta el concepto del Cristo cósmico en el teólogo Leonardo Boff, como realidad que trasciende a los seres humanos, sus adscripciones religiosas, incluso la soteriología. Se aborda, particularmente, la consecuencia de esta idea en la superación del antropocentrismo y en una espiritualidad que considera la importancia de la relación entre Cristo y el universo. El artículo es, además, una lectura crítica desde la tradición reformacional como alternativa a las principales teologías evangélicas de los últimos siglos, que desde el escolasticismo protestante, carecen de una reflexión cosmológica consistente.

Palabras claves: Cristología, Cosmología, creación, Leonardo Boff, reformacional.

\section{Anthropocentrism and Cosmic Christ in Leonardo Boff: a reading from a reformational view}

\begin{abstract}
This article presents Leonardo Boff's theological concept of cosmic Christ as a reality which transcends buman being and their religious and soteriological views. The consequences of this concept in the overcoming of anthropocentrism and a spirituality which considers the importance of relation between Christ and the universe are particularly regarded. Moreover, this article offers a critic view from the reformational tradition as an alternative to the main alternatives among the evangelical theology of the last centuries, especially the scholastic Protestantism which according to the author does not have a consistence cosmic thought.
\end{abstract}

Key words: Christology, Cosmology, creation, Leonardo Boff, reformational.

Licenciado en Teología, Seminario Teológico Presbiteriano José Manuel Ibáñez Guzmán, Chile). Ha publicado los libros, April (Austria, 2012) y Exogénesis (Chile, 2014).

Recibido: 3/Diciembre/2016 - Aceptado: 17/Enero/2017 


\section{Introducción}

Posterior a la Reforma, el carácter cosmológico de Cristo dejó de ser tema para la teología protestante, siendo concebido únicamente como salvador. Esta hipertrofia fundamentalista resultó de la reaparición de una nueva forma de escolasticismo con su dicotomía medieval naturaleza /gracia, cuyo énfasis estaba puesto en las cosas eternas, y no en las terrenas, preocupándose más del alma que del mundo creado por Dios. El problema se produjo, en palabras de Herman Dooyeweerd, "al restringir el alcance de la caída y la redención a lo sobrenatural" (Dooyeweerd 1998: 121). Ejemplo de esto es el cristianismo evangélico y los movimientos carismáticos del siglo $\mathrm{XX}$, siendo sus únicas incursiones en el plano cosmológico, las que buscan combatir la amenaza evolucionista. Desde un punto de vista metodológico, las principales corrientes evangélicas no cuentan con una propuesta teológica de la creación que sea del todo robusta (Spykman, 1994).

A diferencia de lo que percibimos en Martín Lutero cuyo punto de partida era la justificación por la fe, para Juan Calvino existía una unión indisoluble entre soteriología y cosmos, y esto, "no fue el resultado de un proceso dialéctico, sino de la profunda impresión de la majestad de Dios que había moldeado su vida" (Kuyper, 2010: 148). En su obra más conocida y de mayor repercusión hasta el día de hoy, la Institución de la religión cristiana, Calvino (2012) se refiere a la relación entre el verdadero conocimiento y la contemplación de Dios en sus obras:

También debemos comprender que la manera apropiada de buscar a Dios y la actitud que debemos tener no consiste en manifestar una gran curiosidad al examinar su majestad, sino en contemplar sus obras, que nos lo hacen próximo y familiar y que, en cierta forma, nos hablan (Calvino, 2012: 23).

El reformador francés, con una convicción profundamente soteriológica, sostiene que aunque las cualidades de Dios resplandecen en el mundo y son perceptibles por todos, debemos reconocer lo que ellas evocan: tienen un uso y finalidad y ésta se encuentra en que consideremos cómo Dios pone aliento de vida en nosotros.

Más adelante, Abraham Kuyper retoma el factor cosmológico y su conexión con Cristo, producto de una comprensión todoabarcante de la salvación: "El objeto de la obra de redención no está limitado a la salvación de pecadores individuales, sino que se extiende a la redención del mundo y a la reunión orgánica de todas las cosas en los cielos y en la tierra bajo Cristo como su cabeza original" (Kuyper, 2010: 147). Para el tema en cuestión, la postura de Kuyper es relevante debido a que el principio 
fundamental de su obra es el señorío de Cristo sobre todo el cosmos. Este principio continúa siendo el punto de partida del pensamiento reformacional y contituye el leivmotiv de su cosmovisión. Cuando nos referimos al pensamiento reformacional, hablamos del trabajo formulado inicialmente por los teóricos holandeses Abraham Kuyper, Herman Bavinck, Herman Dooyeweerd y D. H. T. Vollenhoven, entre otros. Este movimiento puso énfasis en algunos tópicos como la gracia común, el mandato cultural y las esferas de soberanía, con el fin de construir un discurso que diera respuesta al acontecer social holandés del siglo XIX; cabe decir que con el tiempo se trasladó a Norteamérica. Uno de los mayores exponentes que tiene esta corriente en la actualidad es Albert Wolters, que en su libro La creación recuperada también se refiere a la relación entre Cristo y el cosmos de la siguiente manera: "Hay un sentido en que Cristo es mediador de la creación. Además, el darle a Cristo el título de palabra sugiere una conexión íntima entre Cristo a través de quién y la palabra de Dios por quién el universo fue hecho" (Wolters, 2013: 22).

Otro exponente importante en la línea reformacional, pero poco conocido en Latinoamérica, Gordon Spykman, señala respecto al alcance universal de la Cristología:

La cristología es más que soteriología. Todos los hombres tienen que ver con el Cristo. Porque todas las cosas en él subsisten (Col 1:15-20). Aquí percibimos la demanda universal de la religión bíblica (...). El orden de la creación provee un punto de anclaje óntico para un estilo de vida distintivamente bíblico (Spykman 1994: 197).

A partir de esta óptica reformacional queremos bosquejar nuestra lectura al concepto del Cristo cósmico en Leonardo Boff. No es el único que ha escrito sobre esta idea, pero si es uno de los pocos autores que con el paso del tiempo ha intentado conformar entorno a ella una propuesta a modo de corpus theologicus., que dé respuestas a los avances de la física y a la crisis ecológica de la globalización. Nuestra metodología de trabajo será la siguente: Primero, definiremos algunas consideraciones preliminares a modo introductorio en un breve repaso histórico de su obra. En segundo lugar, revisaremos su propuesta en el plano de la cosmo-génesis, encarnación, resurrección y espiritualidad. Por último, haremos algunas observaciones críticas desde la tradición reformacional, como única alternativa posible en el protestantismo actual. Para esto, confrontaremos una pequeña selección de sus afirmaciones con autores de la tradición que asumimos, demostrando que su preocupación por la recuperación de la idea del Cristo cósmico es necesaria, pero dejando en evidencia que algunos aspectos de su propuesta son, desde nuestra óptica, cuestionables. 


\section{Repaso histórico}

De lo primero que nos percatamos con Leonardo Boff es de la dificultad de hacer un seguimiento bibliográfico a su obra, debido a la gran cantidad de libros y artículos publicados y lo recurrente que es en re-editar textos con correcciones posteriores. Es así que cuando trata un tema, todos los libros que tiene sobre ese asunto, cuentan con una base común que va sufriendo cambios y adiciones, y que son editados con distintos títulos o subtitulos. Su idea del Cristo cósmico no es la excepción.

En el año 1971, Leonardo Boff publica el libro Jesucristo y la liberación del hombre, donde dedica un capítulo titulado El evangelio del Cristo cósmico, compuesto por dos secciones, a revisar a través del método estructuralista la visión del Cristo cósmico que presenta el científico y sacerdote francés Teilhard de Chardin, y un análisis crítico al grado de realidad y de posibilidad de verificación de sus aciettos. Décadas más tarde publica el artículo El Cristo cósmico: la superación del antropocentrismo, de 1999, por $\mathrm{Nu}$ men: revista de estudos e pesquisa da religião, proponiendo algunos avances respecto al concepto, y no sólo cumpliendo una labor documentaria como lo hizo en el libro de 1971. Por último, en el año 2010 aparece Evangelio del Cristo cósmico: Hacia una nueva conciencia planetaria, donde continúa desarrollando su trabajo entorno al concepto, pero esta vez, desde el paradigma ecológico para una nueva ética social.

Aunque la idea del Cristo cósmico como superación del antropocentrismo permea todos sus ensayos sobre el tema, nos acotamos al que quizás es el texto donde de manera más clara esta cuestión se constituye en el eje central: El Cristo cósmico: la superación del antropocentrismo, artículo homónimo publicado por Numen: revista de estudos e pesquisa da religião, y que apareció el mismo año en 10 Palabras clave sobre Jesús de Nazaret, de J. J. Tamayo. En las primeras líneas comienza presentando su tesis (cuya crítica subyace en todo el resto de la obra):

Pertenece a la fe cristológica afirmar que Jesucristo tiene que ver con el misterio de la creación y no solamente con el misterio de la redención. Los textos de las epístolas de Efesios, Colosenses y Hebreos y el prólogo del evangelio de Juan dejan claro que el universo tiene en Cristo su existencia y consistencia. Esta perspectiva es importante porque introduce dos rupturas de grandes consecuencias, ni siempre contempladas debidamente por la teología. Ella supera el eclesiocentrismo, es decir, la realidad de Jesucristo no interesa solamente a los creyentes que se constituyen en Iglesia; tiene que ver también con todos los seres humanos, más allá de sus inscripciones religiosas y culturales. En segundo lugar, ultrapasa el antropocentrismo; Cristo no interesa solamente a los seres humanos; él está vinculado con todos los seres 
y con el entero universo. De aquí se deriva su dimensión cósmica (Tamayo, 1999: 127).

Este artículo ya da indicios de lo que será su ética ecológica y servirá como base para la depuración de su tesis en el Evangelio del Cristo cósmico: Hacia una nueva conciencia planetaria (Boff, 2010). A continuación, de forma muy somera, presentaremos algunos de los puntos principales de su propuesta, explicitada en el artículo ya mencionado.

\section{Cosmo-génesis}

Leonardo Boff reconoce en la cosmogénesis uno de los mayores descubrimientos de la cosmología moderna. La cosmogénesis se entiende como el hecho de que nada en el universo se encuentra acabado, sino que está en constante génesis y expansión: "La evolución no se limita, como aún pensaba Charles Darwin, a los seres orgánicos. Es universal y caracteriza todo el universo que surgió del big bang hace 15 mil millones de años" (Boff, 1999: 127). El universo es una permanente autocreación, generando nuevas formas, cada vez más complejas y ordenadas. El que todo se encuentre en constante génesis significaría que todo viene gestado en el proceso de la evolución; todo lo que existe ya habría pre-existido de alguna forma.

Sobre este proceso de cosmo-génesis, Boff señala un punto a tener en cuenta:

Llegando a un cierto grado de complejidad emerge la vida como autopoiesis (auto-creación y auto-organización) de la materia y de la energía. La materia no tiene solamente masa y energía, sino también información. Esta es cumulativa y crea creciente interioridad y subjetividad. Por eso el universo no significa el conjunto de los objetos, sino la articulación de los sujetos interretro-dependientes (Boff, 1999: 128).

Este fenómeno también se podría aplicar a Jesucristo, llevándonos a comprender la Cristología como cristo-génesis, y esto, por la simultaneidad en el carácter humano y divino de Jesús, siendo la expresión máxima del proceso cosmogénico. Boff reconoce en la intimidad de Jesucristo con Dios un salto hacia arriba y hacia delante, mostrando un dato que la conciencia humana conservaba pero que todavía no se había manifestado con tal expresión: Dios como Padre (y Madre) y todos los seres del universo como sus hijos e hijas. Y no sólo eso, ya que también se comunica como Hijo. Sería por esto que la epístola a los Romanos 8:29 
afirma: "Porque a los que Dios conoció de antemano, también los predestinó a ser transformados según la imagen de su Hijo, para que él sea el primogénito entre muchos hermanos" (Nueva Versión Internacional, 1999).

Según Pierre Teilhard de Chardin, místico estudiado por Boff, hay un elemento crístico en el universo. Este elemento crístico, a medida que va ocurriendo la evolución, brotaría en la conciencia de la persona creyente, hasta que lo asume; por lo tanto, cada cristiano es portador consciente de lo crístico. Desde el momento que el cristiano asume el elemento crístico, este pasa a ser cristológico. Boff lo ve de forma similar, aunque con un alcance mucho más amplio:

Cristo/mesias significa el ungido y el predestinado para cumplir la irrupción de la conciencia de que somos hijos/hijas de Dios. Por el hecho de que irrumpió en Jesús no significa que él tiene el monopolio de esta realidad. Ella es compartida por todos; pero en él emergió en un grado tal de densidad e intimidad que podía verdaderamente decir que él y el Padre son una misma cosa (Boff, 1999: 129).

Aunque las comunidades cristianas son privilegiadas al ser portadoras que han concientizado el elemento crístico, y es por esto que se conforman tales comunidades, no es exclusividad ni monopolio de ellas, ya que está presente y activo en todos los seres humanos: "En todos emerge también en su grado propio, en algunos de forma tan significativa que se hacen referencias crísticas y mesiánicas" (Boff, 1999: 129). Si el cristo cobró conciencia en Jesús quiere decir que ya existía previamente en el proceso cosmogénico y antropogénico.

\section{El plano cósmico de la encarnación}

El misterio de Cristo se nos revela en Jesús de Nazaret, hijo de María, pero éste y su existencia son previas. Boff ve en la encarnación la personificación del elemento crístico. En ella se habría manifestado toda una obra cósmica de sintetización de la conciencia crística en el Hijo hecho hombre que implica un avance significativo del todo y para todos. Jesús sería la convergencia de la evolución, el punto omega. Ese punto permite que hablemos de encarnación, "como total entrega de Dios-Hijo al universo en la realidad concreta del hombre Jesús de Nazaret, capaz de recibir tal autocomunicación divina" (Boff, 1999: 130).

No sólo eso. Según Boff, de algún modo, la encarnación alcanza al resto de los seres humanos, volviéndonos receptores de la auto-comunicación de Dios: 
Con Jesús alcanzó el ápice, en el momento de su toma de conciencia de que es el Hijo bien amado del Padre. En seguimiento a él, nosotros, portadores de semejante capacidad, somos también verbificados. La encamación aparece así como un proceso aún en curso. EI Verbo sigue emergiendo de la materia y en la historia del mundo hasta verbificar el universo entero y introducirlo en el reino de la Trinidad, en el cual todos estarán en el Todo (Boff, 1999: 132).

Casi todos los elementos fueron formados hace millones de años en el interior de las estrellas por medio del proceso llamado nucleo-síntesis. Las galaxias, el planeta y las personas contienen material reciclado de estas estrellas, por lo tanto el mismo Jesús contiene este material, y su cuerpo podría estar formado por polvo cósmico incluso más antiguo que el sistema solar. Cristo adquirió oxígeno, hierro, calcio, y una serie de elementos químicos, cuando se encarnó en la persona de Jesús: "todo eso hace que su encarnación sea realmente cósmica. EI Hijo se revistió de toda esa realidad material cuando emergió de la cosmo-génesis" (Boff, 1999: 131).

En el Concilio de Calcedonia (451 d.C.) se discutió sobre la naturaleza de Cristo. En éste se definió en la categoría dogmática, que él comparte la misma sustancia que nosotros, los hombres. Esto quiere decir, en un sentido cosmológico, que en el nace la vida como en toda persona, y su relación con la Tierra en el aspecto biológico es de la misma forma que la nuestra. Aún más, Boff reflexiona sobre el hecho que en su humanidad también es el resultado de la explosión e inflación inicial y que su origen se encuentra en la Vía Láctea. Nuestro planeta es "el lugar biológico de la irrupción de la divinidad dentro de la materia en evolución" (Boff, 1999: 131).

El hecho de la encarnación vincula a Jesús con el cosmos, pero también lo limita en un sentido espacio-temporal; la encarnación es kenosis. (vaciamiento). Es un hombre, con nacionalidad, y nace y muere en una época determinada. Compartir sustancia en su naturaleza humana, implica que también está expuesto a los avatares de la vida, como los fenómenos geo-climáticos. Estos mismos procesos van seleccionando y acabando con los elementos del ecosistema que no logran adaptarse a los cambios permanentes que éste va sufriendo. Esta sería una dimensión cruel en la cosmo-génesis, que consiste en la permanente tensión en la biósfera por las grandes extinciones que han amenazado la vida en nuestro planeta desde sus orígenes. 


\section{El plano cósmico de la resurrección}

Hay que comprender que la resurrección no consiste en la reanimación de un muerto, es mucho más que eso, Jesús adquiere un cuerpo espiritual; es la realidad futura, de los cuerpos glorificados, hecha presente en Cristo. En el momento de la resurrección, Jesús llega al punto cúlmine del proceso cosmológico en el ser humano; la realización absoluta en su estado pleno; en palabras de Boff, da un salto hasta el término del proceso evolutivo logrando el punto omega. Desde la resurrección vuelve a tener una comunión íntima con el cosmos, sin las limitaciones espacio-temporales de la encarnación. Jürgen Moltmann lo dice de la siguiente manera: "En el resucitado la evolución se convierte en revolución en el sentido original de la palabra” (Moltmann, 1989: 230). Boff va aún más allá, describiendo este hecho como: "El Jesús histórico que era solamente parte del universo, ahora por el evento sagrado de la resurrección asume la totalidad del cosmos" (Boff, 1999: 133).

Es notable la dimensión cósmica que el Nuevo Testamento le atribuye a Cristo. En varios pasajes es llamado Señor (Kyrios) del universo, evidenciando que es en él que todas las cosas, tanto las que están en los cielos como en la tierra, adquieren sentido (Col 1, 15-20) y alcanzan su plenitud (Pleroma). O como afirma G. Ladd: "La restauración final incluye el mundo material (...) Aunque Pablo no desarrolla esta verdad de la redención de la naturaleza, hay una teología bíblica profunda que subyace a la misma" (Ladd, 2002: 742). La cohesión y el orden del cosmos sólo se logran a través del Hijo:

Él es la imagen del Dios invisible; el primogénito de toda creación, porque por medio de él fueron creadas todas las cosas en el cielo y en la tierra, visibles e invisibles, sean tronos, poderes, principados o autoridades: todo ha sido creado por medio de él y para él. Él es anterior a todas las cosas, que por medio de él forman un todo coherente. Él es la cabeza del cuerpo, que es la iglesia. Él es el principio, el primogénito de la resurrección, para ser en todo el primero. Porque a Dios le agradó habitar en él con toda su plenitud y, por medio de él, reconciliar consigo todas las cosas, tanto las que están en la tierra como las que están en el cielo, haciendo la paz mediante la sangre que derramó en la cruz (Colosenses 1:15-20, Nueva Versión Internacional, 1999).

Sobre este pasaje, F. F. Bruce sostiene: "Así como la primera estrofa celebra el papel de Cristo en la antigua creación, la segunda estrofa celebra su papel en la nueva creación, especialmente, con respecto a su obra de reconciliación” (Bruce, 1984: 106). El Cristo resucitado es mencionado no 
sólo como cabeza de la iglesia, sino también como cabeza del cosmos. Esta idea está presente también en la epístola a los Efesios 1,10, aunque exaltándolo principalmente como señor del universo: "para llevarlo a cabo cuando se cumpliera el tiempo, esto es, reunir en él todas las cosas, tanto las del cielo como las de la tierra" (Nueva Versión Internacional, 1999). Sobre este matiz, que se hace aún más evidente en los versículos siguientes, Donald Senior propone algo interesantísimo:

Ahora bien, Efesios 1:22-23 no se limita a repetir lo que se había enunciado en Colosenses, a saber, que Cristo es el señor del universo y la cabeza de la iglesia, sino que subraya que Cristo, a quien Dios ha exaltado sobre todas las cosas, ha sido dado como «cabeza suprema» (literalmente: «cabeza sobre todas las cosas») a la iglesia. El versículo 23a sigue enunciando que esa iglesia es también el cuerpo de esa cabeza, como había hecho Colosenses 1:15. Pero parece que se ha introducido un matiz nuevo de pensamiento. El acento recae sobre el señorío cósmico de Cristo en sí mismo y por sí mismo, independientemente de cualquier conexión con la iglesia (Senior \& Stuhlmueller, 1985: 273).

Así como varios textos del Nuevo Testamento (Efesios, Colosenses) ponen de manifiesto la relación de Cristo con el cosmos como quien es el centro y la fuente en la cual todo encuentra sentido, también el Evangelio copto de Santo Tomás hace referencia a esto en el agraphon del logion 77: "Yo soy la luz que está sobre todas las cosas; yo soy el universo; el universo salió de mí y el universo retornó a mí; hiende la leña y yo estoy dentro de ella; levanta la piedra y yo estoy debajo de ella" (Boff, 1999: 135). El Cristo cósmico es a la vez universal, y en tanto entramos en contacto directo y estrecho con la naturaleza, estamos entrando en contacto también con el Cristo resucitado, reconciliador del universo con Dios, y en quien se unifica toda la creación:

Cuando abrazamos al mundo, cuando penetramos en la materia, cuando sentimos el campo de las fuerzas y de las energías, cuando hacemos los trabajos más penosos y humildes como partir la leña o levantar piedras, estamos en contacto con el Cristo resucitado y cósmico. Aquí se nos abre el espacio para una experiencia inefable de comunión concretísima con el Cristo total (Boff, 1999: 135).

\section{E1 plano cósmico de la espiritualidad}

Para Boff, la forma más concreta de comunión con la totalidad de Cristo se expresa en el sacramento de la Eucaristía; si se acepta desde la posición Católica-romana de la transubstanciación. Esto, porque así como 
Chardin lo percibió, la Eucaristía prolongaría la encarnación, haciendo perdurable en el tiempo la unión de Cristo con los elementos cósmicos. En el pan y el vino está la materia del universo, presentándose, en la Eucaristía, como el cuerpo cósmico de Cristo. Esto lo podemos ver claramente en su Misa sobre el mundo, o también titulada Himno del Universo, que estando en medio de una expedición en el desierto de Gobi en China e imposibilitado de celebrar la Eucaristía para la Fiesta de la Transfiguración, eleva una plegaria de la que citamos un extracto:

No tengo ni pan, ni vino, ni altar. Otra vez, Señor. Ya no en los bosques del Aisne, sino en la estepas de Asia. Por cual trascenderé los símbolos para sumergirme en la pura majestad de lo Real, y yo, tu sacerdote, te ofreceré el trabajo y la aflicción del mundo sobre el altar de la Tierra entera. A lo lejos el sol ha terminado de iluminar las fronteras del primer Oriente. Una vez más, bajo el manto ondulante de sus fuegos, la superficie de la tierra se despierta, se estremece, y reanuda su mágico trabajo. Colocaré sobre mi patena, oh mi Dios, la cosecha anhelada de este nuevo esfuerzo. Derramaré en mi cáliz el zumo de todos frutos que hoy habrán madurado (Chardin, 1996: 1).

Pierre Teilhard de Chardin ve lo sacro en el universo, bajo la idea que los mismos elementos presentes en el pan y el vino, están presentes en la inmensidad del cosmos; no sólo la presencia de las sustancias, sino de Cristo mismo. La experiencia mística convertida en rito, asegurando, como decía Máximo el Confesor que "el mundo es un templo cósmico y el hombre su sacerdote", y en un sentido muy parecido Metropolita Filaretes de Moscú, afirmando que "el hombre ha sido creado para entrar en el cosmos como un rey y pontífice" (Evdokimov, García \& Presa, 1991). Como vemos, el Cristo cósmico no sólo tiene repercusiones cristológicas sino también antropológica, y muy fuertes.

Esta perspectiva cambia radicalmente la forma en que el cristiano vive su espiritualidad, porque lo llevará a terminar con cualquier noción pietista de su relación con Cristo y el mundo. En esta misma línea, Herman Ridderbos dice que: "la iglesia es por medio de él (1 Cor 8:6) y vive para él en la totalidad de su existencia" (Ridderbos, 2000: 107). Este Cristo cósmico abre nuevos horizontes no sólo para la Teología, sino también para la experiencia cristiana. Es por ello que asertivamente Leonardo Boff concluye:

No necesitamos abandonar el mundo para encontrar al Señor. Él lo penetra y lo hace grávido de su presencia, desde los primeros movimientos de las energías primordiales y de los elementos materiales. Ahí estaba ya en acción la cristo-génesis. Por lo tanto, hay que superar definitivamente el antropocentrismo que reduce el significado de la encarnación (Boff, 1999: 136). 
Desarrollar una espiritualidad teniendo en cuenta el sentido cósmico de la Cristología, nos ligará, entre otras cosas, a una conciencia ecológica, tan necesaria en este tiempo de industrialización desmedida y del avance inmobiliario causando un serio impacto ambiental (Boff, 1999). Qué decir de la producción energética en el sur de nuestro país, y sus consecuencias en el daño hídrico y forestal, acabando con nuestros ríos y bosques, y replegando comunidades pehuenches hacia la cordillera. El cristiano que adopta una espiritualidad considerando la realidad del Cristo cósmico será movido a un profundo respecto por la creación, procurando su cuidado y conservación ${ }^{1}$. Esto es fundamental si verdaderamente deseamos la preservación de todo lo creado y no su usufructo indiscriminado en aras del progreso.

Por último, reconoce en las distintas tradiciones religiosas y espirituales otras manifestaciones de lo crístico, en figuras destacables que alentaron a pueblos enteros en su camino a Dios; estos serían otras expresiones del Cristo cósmico en la historia. Esta idea, ya cercana a una especie de sincretismo cristocéntrico, la anuncia desde el inicio del artículo, "esta dimensión cósmica permite descubrir las huellas de Cristo en otras figuras humanas, en la realidad histórico-social" (Boff, 1999: 127), y la desarrollará un poco más en su ensayo posterior: Evangelio del Cristo cósmico: Hacia una nueva conciencia planetaria, en el que propone que las distintas tradiciones religiosas son parte de una espiritualidad de la globalización. En este último, al punto de citar la fórmula Gloria al Uno del maestro yogui de Brasil, Hermógenes: "Oré al Cristo / Y fue Buda quien me atendió. / Llamé a Buda / Y fue Krishna quien me respondió" (Boff, 2010: 77).

\section{Conclusiones}

Boff no logra superar el paradigma moderno. Esto lo podemos corroborar desde su primer acercamiento al tema, en el capítulo "Evangelio del Cristo cósmico" del libro Jesucristo y la liberación del hombre. En la segunda parte busca "analizar críticamente el grado de realidad y de posibilidad de verificación de los aciertos de Teilhard sobre el Cristo cósmico" (Boff, 1981: 593). Cuando Boff apela al grado de realidad se está refiriendo al grado de cientificidad. Intenta conciliar lo que para nosotros es irreconciliable: el elemento mítico con lo que él llama realidad, reconociendo el mito en su relación con la experiencia cristiana y como interpretación de esa realidad ${ }^{2}$.

1 Uno de los textos más recomendables sobre el tema es la encíclica Laudato si' del Papa Francisco.

2 Posición similar a la de Rudolph Bultmann.

VERITAS, Nº 36 (Abril 2017) 
Es importante tener en cuenta esto ya que vemos algo parecido en el artículo bajo nuestro escrutinio. Absorbe los principios modernos de forma totalmente acrítica, buscando conciliarlos con la tradición de la iglesia, desde las teologías juanina y paulina hasta el Concilio de Calcedonia. Sobre esto, Marcelo Carlesso (2010) ve un impacto del evolucionismo en la Cristología brasileña, justamente, a partir del pensamiento de Teilhard de Chardin. En su artículo titulado O evolucionismo e seu impacto na cristología brasileira e latino-americana: retrospectiva e prospectiva (El evolucionismo y su impacto en la Cristología brasileña y latinoamericana: retrospectiva y prospectiva) concluye que 1) hay un gran número de libros de Teilhard traducidos a la lengua portuguesa y 2) hay un gran interés de los investigadores en la obra de Chardin, principalmente en el área de la Filosofía, seguida por la Teología. Por lo tanto, el caso de Boff no es aislado, responde a un fenómeno mayor que se puede percibir, según Carlesso, en la influencia del pensamiento de Chardin en obras teológicas latinoamericanas, y especialmente brasileñas. Algunos de los autores influenciados en su teología por Chardin serían Jon Sobrino, Frei Betto, Francisco Bravo, Leonardo Boff y Urbano Zilles.

Está claro que el propósito de Boff es hacer dialogar a la Teología con otras ciencias, plausible por lo demás, si se trabaja respetando las reglas internas de cada disciplina, pero falla al subordinar la esfera teológica a la de las ciencias naturales. Es ahí que el aporte de la tradición reformacional, principalmente de Abraham Kuyper y Herman Dooyeweerd con la soberanía de las esferas, cobra mayor valor, al hacer que la Teología hable por si sola, sin someterla al visto bueno de otras ciencias, ni corroborando sus resultados por métodos que no le pertenecen. Kuyper es claro cuando aplica este principio a las ciencias diciendo:

Cada ciencia tiene que mantener la conexión más estrecha con su sujeto y obedecer estrictamente las exigencias de su propio método; y solamente cuando esté estrictamente constreñida por este doble vínculo, la ciencia podrá moverse libremente. Porque la libertad de la ciencia [está] en ser libre de todos los lazos innaturales - innaturales porque no están arraigados en su principio vital (Kuyper, 2010: 156).

Algo similar es lo que dice Dooyeweerd, cuando se refiere de modo general a la autonomía de cada esfera: "La soberanía de las esferas garantiza para cada esfera (...) una intrínseca naturaleza y ley de vida. Y con esta garantía provee la base para una esfera original de autoridad y competencia derivada no de la autoridad de cualquier otra esfera" (Dooyeweerd, 1998: 50). Ahí yace el problema en la propuesta de Boff, porque naturaliza el método científico moderno de las ciencias naturales como parte de su 
quehacer teológico; algo que tampoco es nuevo, y que domina varios espacios académicos. Dooyeweerd ya lo advierte al señalar:

Los humanistas estaban convencidos de que sólo el método de pensamiento desarrollado por las matemáticas modernas y la ciencia natural enseña a los hombres a conocer la realidad como es "en sí misma", despojada de todas las adiciones subjetivas y errores de la conciencia humana de las que somos víctimas en la experiencia ingenua de la vida cotidiana. ¡El nuevo ideal de la ciencia llegó con grandes pretensiones! Sólo él podía develar el verdadero orden y coherencia de la realidad (Dooyeweerd, 1998: 164).

Por último, podemos concluir que Leonardo Boff si acierta en su crítica al antropocentrismo, y por ende, al eclesiocentrismo, al presentarnos al Cristo cósmico como realidad que ultrapasa a los seres humanos. Esta concepción cosmológica que ya estaba presente en las teologías juanina y paulina y que vagamente ha estado presente en las teologías de los últimos siglos es recuperada con el objetivo de tener una comprensión omni-abarcante del Dios-Hijo y su lugar en el universo, para que nos mueva a una espiritualidad cósmica y renovada. Eso si tropieza, desde nuestra óptica, al llevar esta idea a su grado sumo, reconociendo expresiones del Cristo cósmico en otras figuras que han tenido un rol destacable en la historia. No será un "sincretismo fácil" (Boff, 2010: 77) según sus palabras, pero finalmente si lo es, al intentar comprender la figura del Cristo cósmico en una espiritualidad de la globalización. Esa espiritualidad de la globalización a la que se refiere Boff, sería lo que el filósofo Nicholas Wolterstorff define como religión transmutada en religión sin religión, "una religión cuyo contenido es fundamentado sólo en la razón y no en las particularidades de la revelación (...) o tradición” (Wolterstorff, 2015: 304). Wolterstorff dice que esta será una religión que abandonará sus particularidades con el fin de tener aceptación universal, una religión compartida por todos que buscará llevar al mundo a la paz eterna: "mientras la humanidad progresa hacia la completa racionalidad, esta es la religión que cada vez más abrazará" (Wolterstorff, 2015: 304). Haciendo eco de sus palabras, rechazamos la idea de Boff porque creemos, desde nuestra óptica reformacional, que el cristianismo es una religión por naturaleza exclusivista, y que su lugar en la globalización no se dará en tanto transmute a sí misma en una religión no particularista, sino en el reconocimiento y la aceptación de sus particularidades.

\section{REFERENCIAS}

-Nueva Versión Internacional (1999). Biblia. Miami: Vida.

-Boff, L. (1981). Jesucristo y la liberación del hombre. Petrópolis: Vozes. 
-Boff, L. (1999). El Cristo cósmico: la superación del antropocentrismo. Numen: revista de estudos e pesquisa da religiäo, 2(1), 125-139.

-Boff, L. (2010). El evangelio del Cristo cósmico: Hacia una nueva conciencia planetaria. Madrid: Trotta.

-Bruce, F. (1984): Colossian Problems: Part 2: The 'Christ Hymn' of Colossians 1:15-20. Dallas: Biblioteca Sacra.

-Calvino, J. (2012). Institución de la religión cristiana. Grand Rapids: Desafío.

-Carlesso, M. (2010). O evolucionismo e seu impacto na cristologia brasileira e latino- americana: retrospectiva e prospectiva. En C. Frankenberg (ed.), XI Salão de Iniciaşão Científica - PUCRS (pp. 1792-1794). Porto Alegre: EDIPUCRS.

-Chardin, P. de (1996). El himno del universo. Madrid: Trotta.

-Dooyeweerd. H. (1998): Las Raices de la cultura occidental: las opciones pagana, secular y cristiana. Barcelona: CLIE.

-Evdokimov, P., García, L., \& Presa, M. D. (1991). El arte del ícono: Teología de la belleza. Madrid: Claretianas.

-Kuyper, A. (2010). Conferencias sobre el Calvinismo. San José: CLIR.

-Ladd, G. (2002). Teología del Nuevo Testamento. Barcelona: CLIE.

-Moltmann, J. (1989). Der Weg Jesu Christi: Christologie in messianischen Dimensionen. Munich: Kaiser.

-Ridderbos, H. (2000). El pensamiento del apóstol Pablo. Grand Rapids: Desafío.

-Senior, D. \& Stuhlmueller, C. (1985): Biblia y misión. Navarra: Verbo Divino.

-Spykman, G. (1994). Teologia reformacional. Jenison: The Evangelical Literature League.

-Tamayo, J. (1999). 10 Palabras clave sobre Jesús de Nazaret. Navarra: Verbo divino.

-Wolters, A. (2013). La creación recuperada. Medellín: Poiema.

-Wolterstorff, N. (2015). Liberalism and Religion. En S. Wall (ed.), The Cambridge Companion to Liberalism (pp. 282-304). Cambridge: Cambridge University Press.

Sumario: Introducción; 1. Repaso histórico; 2. Cosmo-génesis; 3. El plano cósmico de la encarnación; 4. El plano cósmico de la resurrección; 5. El plano cósmico de la espiritualidad; Conclusiones; Referencias. 